\title{
CONSTRUINDO CAMINHOS DE LEITURA: RETRATOS DE UMA EXPERIÊNCIA EM EDUCAÇÃO À DISTÂNCIA
}

\author{
BUILDING READING TRACKS: PORTRAITS OF AN \\ EXPERIENCE IN DISTANCE EDUCATION
}

\author{
Eliane Travensoli Parise Cruz \\ Elenice Parise Foltran ${ }^{*}$
}

\begin{abstract}
RESUMO
O compromisso do trabalho com a leitura e o seu ensino tem grande importância no interior da escola. Embora existam muitas discussões e estudos ainda se constata uma enorme ausência quanto a ações pedagógicas que produzam resultados capazes de reverter o contexto das deficiências em torno da temática. Assim sendo, este trabalho teve como objetivo subsidiar teoricamente os alunos do Curso de Pedagogia - modalidade EADpara implementar atividades de leitura em suas aulas por meio do curso de Extensão Criando ações potencializadoras de leitura integrante do Plano Inovador de Formação em Ludicidade e Educação, evento de extensão, ofertado pelo Programa extensionistaLaboratório Lúdico Pedagógico - Lalupe. Para tanto, foram desenvolvidas atividades online - em ambiente virtual AVA - a fim de realizar estudos sobre a concepção de leitura, a importância do professor mediador de leitura, as estratégias de leitura, a criação de atividades com leitura para futuras aplicações. O estudo ainda traz uma análise textual de um texto narrativo escolhido para o ambiente virtual a fim de respaldar uma metodologia capaz de contribuir para a efetivação de ações pedagógicas primando pelos sentidos. A formação docente necessita de novas estratégias, novos compartilhamentos, novas experiências e proporcionar este ambiente leitor é responsabilidade emergente para o contexto escolar.
\end{abstract}

Palavras-chave: Leitura. Estratégias de Leitura. Prática Pedagógica. Educação a Distância. Extensão

\begin{abstract}
The commitment of reading work's and its teaching has great importance in school. Although there are many discussions and studies there is a huge absence of pedagogical actions that produce results that can reverse the lack of skills around the theme. Therefore, this study aimed to theoretically support the students of the Pedagogia Course - EAD - to implement reading activities in their classes through the extension course "Creating potentiating actions of reading" (Criando ações potencializadoras de leitura), as part of "Innovative Training Plan in Playfulness and Education" (Plano Inovador de Formação em Ludicidade e Educação), extension event, offered by the extension program_- LALUPE - Pedagogical Ludic Laboratory (Laboratório Lúdico Pedagógico). Therefore, activities were conducted online - AVA in virtual environment - in order to conduct studies on the design of reading, the importance of the tutor of reading, the reading strategies, the creation of reading with activities for future applications. The study includes a textual analysis of a narrative text chosen for the virtual environment to support a
\end{abstract}

\footnotetext{
" Professora do Departamento de Métodos e Técnicas de ensino/UEPG. Mestre em Educação. Graduação em Letras. elianeparise@gmail.com

" Professora do Departamento de Educação/UEPG. Mestre em Educação. Graduação em Pedagogia. Coordenadora do Laboratório Lúdico Pedagógico- LALUPE. epfoltran@gmail.com
} 
methodology capable of contributing to the realization of educational activities excelling by the senses. So, the teacher training needs new strategies, new shares, new experiences in order to provide a reading environment for the school environment has huge responsibility for the school.

Keywords: Reading. Reading Strategies. Pedagogical Practice. Distance Education. Extension

\section{Introdução}

Formar o aluno-leitor: este é o compromisso da escola e do professor, porém há algumas questões a considerar neste contexto: Como formar leitores em uma época em que os livros concorrem com outras ferramentas do mundo virtual? Como despertar o gosto pela leitura? Como motivar alunos a ler livros literários não por obrigação ou necessidade, mas por fruição e prazer? Qual o espaço da leitura e como ela é trabalhada nas salas de aula?

São indagações que surgem quando se refere ao universo da leitura, há uma inquietude pela sua falta e essa preocupação é confirmada pelas diversas áreas de ensino quando os alunos são requisitados a desempenhar determinadas funções tendo como elemento base a leitura.

Assim surge a necessidade de promover ações capazes de reverter o quadro atual da falta de leitura dos envolvidos no processo ensino-aprendizagem, pois o que se verifica na prática cotidiana é a falta de metodologias para trabalhar com questões de leitura, pois parece prevalecer um trabalho ainda espontaneísta com o texto na sala de aula, no qual as perguntas de leitura nascem muito mais da intuição do professor ou do livro didático do que do seu efetivo conhecimento sobre as teorias que subsidiam essa prática. (HILA, 2009, p.152)

Embora existam muitas discussões e estudos sobre o tema Leitura ainda se constata uma enorme ausência de ações pedagógicas que produzam resultados capazes de reverter o contexto das deficiências em torno das questões subjacentes a ela. Assim sendo, o trabalho com a leitura precisa ser ressignificado, isto porque as aulas ficam restritas a atividades burocráticas, sem propósitos definidos e consequentemente ocasionam a aversão à leitura, vistas como vazias de significados e distante de uma prática social.
No documento elaborado pela SEED/ $\operatorname{DEB}(2012$, p. 07), explicita-se um exemplo de burocratização da leitura como tentativa totalmente administrativa, geralmente intermediada pelo professor. Este explica de antemão a interpretação correta do texto aos alunos e a leitura deste funciona como etapa para a realização de atividades, cujo cumprimento obedece a uma previsibilidade determinada. A interpretação do professor tem por base suas experiências de leituras e, deste modo, conduzem a tentativas inúteis e falaciosas de acertar a única interpretação do texto já que se tratam de leitores com histórias e experiências distintas.

Também os produtos requeridos (questões sobre o texto; resumo; preenchimento de fichas, elaboração de desenhos, etc.) tornam-se carro-chefe desse tipo de estratégia pedagógica, utilizada em praticamente todas as disciplinas. O contato leitor-texto, neste caso, torna-se algo secundário ou, em muitos casos, dispensável do ponto de vista do estudante, que almeja cumprir a tarefa e não debruçar-se sobre o texto. (SEED/DEB, 2012, p.07)

Desta forma, compreende-se que a leitura praticada na escola é vista como um ato mecânico, de decifração do código escrito, uma atividade desprovida de significado que serve para preencher fichas, para responder a um roteiro de questões, para estudar o texto ou servindo ainda como atividade pretexto para exercícios gramaticais propostos pelo livro didático.

Outro exemplo da falta de comprometimento frente à formação do sujeito-leitor são atividades do tipo leitura livre, o aluno usa o tempo de sua leitura com o tipo de texto de que mais gosta. O que se constata, em alguns casos, que esse tipo de estratégia não forma leitores, apenas exige que leitores e não-leitores durante tantos minutos do dia escolar leiam ou ocupem o tempo com algum tipo de texto, 
uma atividade desprovida de objetivos e metas para a formação de sujeitos-leitores.

É preciso então romper com velhas metodologias: de que a aula de leitura é pura decifração do código escrito, exercício enfadonho e descontextualizado de uma prática social, porém ela é ferramenta importante para a aquisição do conhecimento que leva ao questionamento, à investigação, às descobertas do mundo e à vida.

Parte-se, portanto, da proposição de que se os futuros professores tiverem acesso às informações sobre leitura, enquanto processo de interação, sobre as estratégias de como planejar uma aula de leitura será possível auxiliar na elaboração de atividades planejadas com objetivos traçados para a compreensão dos textos estudados.

Neste sentido, foram objetivos deste trabalho:

Contribuir na formação do sujeito-leitor compreendendo a importância da leitura na vida pessoal, social e profissional para que seja ferramenta de uso constante;

Subsidiar teoricamente os alunos do Curso de Pedagogia, através do curso de extensão Criando ações potencializadoras de leitura, com possibilidades teórico-metodológicas referentes à leitura;

Possibilitar o contato com as estratégias de leitura para possibilitar o planejamento de ações potencializadoras em suas aulas;

Sensibilizar os envolvidos no tema a fim de pensar, criar e agir sobre as questões de leitura no fazer pedagógico;

Criar espaço para a troca de experiências entre os alunos participantes do curso;

Familiarizar os alunos com a análise de textos narrativos.

Para a efetivação do referido estudo, traçou-se um percurso teórico-metodológico que compreendesse inicialmente uma abordagem sobre a contextualização do processo de leitura enquanto produção de sentido, a importância do professor mediador de leitura, a compreensão das estratégias de leitura bem como a elaboração de atividades com leitura para posterior aplicação.

Na sequência, na metodologia, foi esclarecido o funcionamento do curso on-line analisando efetivamente as questões de leitura a partir do texto Dormir fora de casa de Ronaldo Simões Coelho, cujas atividades foram direcionadas aos alunos do Ensino Fundamental - séries iniciais ( $1^{\circ}$ ao $5^{\circ}$ ano).

\section{Entendendo a leitura no contexto escolar}

Adentrar no mundo dos livros, no sonho, no encantamento, viver as emoções contidas nas palavras do outro, descobrir um universo de sensações e sentimentos, estas são algumas ações que se pode sentir através da leitura.

É preciso então compreender a leitura como um ato dialógico, interlocutivo, que envolve demandas sociais, históricas, políticas, econômicas, pedagógicas e ideológicas de determinado momento. Ao ler, o indivíduo busca as suas experiências, os seus conhecimentos prévios, a sua formação familiar, religiosa, cultural, enfim, as várias vozes que o constituem. (DCEs,2008 p.56)

Em se tratando de interação, Bakhtin (1992, p.113) esclarece: "Na realidade, toda palavra comporta duas faces. Ela é determinada tanto pelo fato de que precede de alguém, como pelo fato de que se dirige para alguém. Ela constitui justamente o produto da interação do locutor e do ouvinte. Toda palavra serve de expressão a um em relação ao outro."

Porém, nem todos os alunos tiveram "uma história de leitura; uma mãe disponível para contar histórias para a criança e de um pai que levanta os olhos de sua papelada para acolher as indagações de seus filhos"(SAVELI, 2007, p.117), este perfil está distante do contexto da maioria dos alunos. Muitas vezes, a escola e o livro didático são as únicas fontes para a experiência com a leitura.

A leitura competente, seja ela para fruição, seja para informação, seja com objetivos técnicos, é um processo que, embora possa ser orientado pela família e deva ser orientado pela escola, absolutamente não se desenvolve sem que se estabeleça o contato direto entre leitor e texto. (KRAMER, 2000, p.18).

Diante disso decorre a necessidade de envolver os alunos na atmosfera de diversas e variadas leituras sendo capazes de compreender e interagir com o texto nas práticas sociais de leitura. 


\section{A leitura e a produção de sentidos}

Segundo Cagliari (1997, p.149), “a leitura é a realização do objetivo da escrita. Quem escreve, escreve para ser lido". É, certamente, através das práticas de leitura que o conhecimento se desvela, que se desenvolve a criatividade, o encantamento, o sonhar, o fantasiar e o imaginar.

É nesse universo de encantamento da leitura que os alunos são capazes de inserir-se nas palavras do outro, encontrar o alento para as suas dúvidas, suas inquietações e também a ampliação do conhecimento.

Antônio Cândido quando aborda a importância da literatura enfatiza que ela constitui-se fator indispensável de humanização; pois possibilita o exercício da reflexão, a aquisição do saber, a boa disposição para o próximo, o afinamento das emoções, a capacidade de penetrar nos problemas da vida, o senso da beleza, a percepção da complexidade do mundo e dos seres, o cultivo do humor. (1995 p. 249)

Já para Bellenger(1978) citado por Kleiman(1996, p.15)

Ler é identificar-se com o apaixonado ou com o místico. É ser um pouco clandestino, é abolir o mundo exterior, deportar-se para uma ficção, abrir o parêntese do imaginário. Ler é muitas vezes trancar-se (no sentido próprio e figurado). É manter uma ligação através do tato, do olhar, até mesmo do ouvido (as palavras ressoam). As pessoas lêem com seus corpos. Ler é também sair transformado de uma experiência de vida, é esperar alguma coisa. É um sinal de vida, um apelo, uma ocasião de amar sem a certeza de que se vai amar. Pouco a pouco o desejo desaparece sob o prazer. (BELLENGER, 1978, p. 17)

Assim, percebe-se que os alunos, inseridos no universo da leitura, são capazes de perceber o mundo que os cercam com seus medos, conflitos, dúvidas ou, até mesmo, a fuga para outros espaços; essa busca pelas palavras do outro pode reportar a horizontes diferentes tanto ao nível da busca pelas respostas quanto pelo deslumbramento das histórias vividas.

Martins (1988, p. 30) afirma que a leitura é uma experiência individual sem demarcações de limites, que não depende somente de decifração de sinais gráficos, mas de todo contexto ligado à experiência de vida de cada ser, para que ele possa relacionar seus conhecimentos prévios com o conteúdo do texto e, assim, construir sentidos.

Corroborando com Foucambert (1998) o ato de ler implica a criação de significados às informações que o leitor tem, àquilo que ele já sabe. Por sua vez, Solé (1998, p.72) afirma: Quem lê deve ser capaz de interrogar-se sobre sua própria compreensão, estabelecer relações entre o que lê e o que faz parte do seu acervo pessoal, questionar seu conhecimento e modificá-lo, estabelecer generalizações que permitam transferir o que foi aprendido para outros contextos diferentes.

Desta forma, percebe-se que toda leitura pressupõe que o leitor faça uso de certos conhecimentos relacionados ao texto. E ela é uma prática interativa, na medida em que exige a participação do leitor, com sua vivência e suas experiências na construção, interpretação e reconstrução de sentidos.

\section{A importância do professor mediador de leitura}

Bellenger(1978)citado por Kleiman(1996, p. 15), autor francês, já dizia que "para formar leitores, devemos ter paixão pela leitura[...]" Ninguém faz aquilo de que não gosta, a não ser por obrigação; disso decorre a necessidade de o professor ser leitor, ler para e como seus alunos, rever os objetivos de leitura, pois o que eles leem quase sempre corresponde aos objetivos, aos interesses de suas leituras.

A leitura só terá sentido se o professor demonstrar a importância dela como prática social, todo o empreendimento frente a busca de estratégias para a compreensão dos significados explícitos e implícitos, para o desenvolvimento do hábito e o gosto pela leitura só terá sentido se o professor fizer desta atividade algo prazeroso e como descoberta de novos horizontes do saber.

Compreender a leitura e o que é ensiná-la implica falar sobre ela, ser um leitor que atua verdadeiramente como sujeito no processo de produção de sentido e que sente prazer em interagir com o autor do texto.

"O leitor não recebe pronto o significado de um texto, ele o constrói, gradualmente".(Kleiman, 2000, p.35 ) Então, cabe ao professor mediar os 
alunos nessa construção, seja apontando pistas contidas no texto, seja fazendo perguntas que os levem a refletir mais sobre o assunto abordado, ou orientando-os nas relações que podem estabelecer entre o texto e o contexto histórico-social de leitura.

Uma leitura atenta do texto pressupõe o trabalho numa ação compartilhada, buscando pistas no texto e as relacionando a possíveis significados, com base em suas experiências, suas histórias de leituras. Ensinar a ler é criar, então, uma atitude de expectativa prévia com relação ao conteúdo referencial do texto. Ou seja, é mostrar ao aluno que quanto mais ele fizer previsão do conteúdo, maior será sua compreensão; é ensiná-lo a se autoavaliar constantemente durante o processo, para perceber quando perdeu o fio da leitura e como pode recuperá-lo; é ensiná-lo a utilizar múltiplas fontes de conhecimento - lingüísticas, discursivas, enciclopédias - para resolver falhas momentâneas no processo. (KLEIMAN, 1996 grifos nossos).

Trabalhar com a leitura é superar a decodificação do código, do aspecto gráfico-fônico, é exercitar os mecanismos de compreensão e interpretação, auxiliando no levantamento de hipóteses possíveis e na confirmação ou refutação das suas ideias a fim de atribuir sentido e significado à leitura realizada.

É nesse ponto que se destaca a figura do professor como mediador para que os alunos possam elaborar suas inferências durante o processo de leitura. Numa leitura compartilhada os alunos são naturalmente conduzidos ao uso de estratégias cognitivas que auxiliam a entender o texto. Essas estratégias implicam conhecimentos prévios do leitor quanto à natureza da escrita, ao gênero textual e ao assunto abordado no texto.

Daí a importância de o professor estar sempre planejando situações de ensino em que os alunos possam adquirir tais conhecimentos, lembrando-se de que os diversos assuntos que permeiam o dia a dia dos alunos supõem conhecimento de mundo.

\section{Trabalhando com a leitura}

Para o planejamento das atividades de leitura, é importante compreender que a metodologia adotada nas aulas deve privilegiar os conhecimentos prévios dos alunos e o professor deve estar atento às singularidades; direcionar as atividades a fim de gradualmente ascender às etapas de leitura e assim criar as estratégias para a produção de sentidos.

Em relação às estratégias de leitura, a atuação do professor é decisiva na formação do leitor autônomo sendo capaz de posicionar-se diante do texto, compreendendo-o, a leitura é uma das ferramentas imprescindíveis para apropriação de novas aprendizagens.

Neste contexto, serão expostas sucintamente algumas estratégias de leitura indicadas por Solé (1998) e Delmanto (2007) que poderão ser trabalhadas no momento da leitura em sala de aula.

Antes da leitura, é preciso identificar as finalidades da leitura (com que objetivos se vai ler) seja para procurar informações, por prazer, para conhecer determinado assunto, para atualizar-se, para seguir instruções ou para revisar o próprio texto.

Também antecipar as informações que podem estar no texto a ser lido a partir do título, do tema abordado, do autor, do gênero textual; antecipar o tema ou ideia a partir do exame de imagens (fotos, gráficos, mapas, tabelas, ilustrações).

E ainda ativar conhecimentos prévios: incentivar os alunos a exporem o que sabem sobre o assunto/conteúdo e/ou forma do texto.

Durante o processo de leitura, é importante inferir, construir o significado de palavras ou expressões a partir do contexto da frase; chegar a conclusões que não foram explicitadas com base em outras leituras, experiências de vida, crenças e valores. Levantar e checar hipóteses, a respeito da sequência do enredo, da exposição ou da argumentação; confirmar, rejeitar ou reformular hipóteses anteriormente criadas. Localizar informações (explícitas ou implícitas no texto), situar quem é o autor, de que lugar (físico/social), de que época, em que situação, com que finalidade; em qual suporte o texto foi publicado (jornal, revista, livro, panfleto, folheto).

É importante também localizar informações para a compreensão do texto ou para fins de estudo; identificar palavras-chave para definição de conceitos; localizar informações relevantes para determinar a ideia central do texto e relacionar as informações com outras leituras para se chegar a possíveis conclusões.

E depois da leitura, as atividades devem conduzir os alunos a extrapolar, ir além do texto, projetar o sentido do texto para outras vivências e outras 
realidades; relacionar informações do texto com o conhecimento cotidiano. Realizar outras atividades, cujos objetivos sejam voltados para as práticas de linguagem. Assim a leitura integrará um espaço de efetivo uso nas práticas sociais.

As ações acima propostas mobilizam a gestão, no cotidiano da sala de aula, de um ambiente que promova fascinação, investigação, questionamentos e descobertas. O desafio posto acontece no sentido de criar e recriar, no espaço do saber, pequenas iniciativas do fazer pedagógico que somadas podem alcançar a configuração da aprendizagem significativa.

\section{Metodologia}

Tendo em vista que a leitura é uma atividade significativa, prazerosa, desafiadora e deve ser trabalhada de forma planejada, organizada, de forma responsável e competente, o curso on-line Criando ações potancializadoras de leitura teve como intenção principal subsidiar teórica e metodologicamente os alunos do curso de Pedagogia - EAD - através de atividades interativas.

A aplicação da aula de leitura foi efetivada através de diversas ações pedagógicas, assim como foi permeado pela pesquisa bibliográfica e documental, tendo como base a pesquisa-ação que pode ser definida, segundo Thiollent, 1985, apud Gil (1996, p. 60), como:

[...] um tipo de pesquisa com base empírica que é concebida e realizada em estreita associação com uma ação ou com a resolução de um problemas coletivo e no qual os pesquisadores e participantes representativos da situação ou do problema estão envolvidos de modo cooperativo ou participativo.

Desta forma, considerou-se importante utilizar este método de pesquisa, justamente porque a investigação partiu de uma situação problema de estudos a fim de intervir em contextos reais de uso da prática leitora no cotidiano escolar.

\section{Retratos de uma experiência}

A elaboração de atividades de leitura, realizada em ambiente virtual, contou com 24 (vinte e quatro) alunos do curso de Pedagogia - EAD da Universidade Estadual de Ponta Grossa - UEPG.
Inicialmente, cada aluno deveria assistir ao vídeo Os fantásticos livros voadores do Sr. Lesmorre e depois participar e interagir com seus colegas em um fórum sobre o papel do professor mediador de leituras.

$\mathrm{Na}$ sequência, realizar leituras de textos que proporcionassem o conhecimento sobre a importância da leitura no contexto escolar, bem como a necessidade do professor mediador de leitura, o conhecimento sobre as etapas e estratégias de como trabalhar a leitura em aula com alunos do Ensino Fundamental $\left(1^{\circ}\right.$ ao $5^{\circ}$ ano $)$ e também escolher um texto narrativo de sua preferência para planejar atividades de leitura, tais ações foram orientadas pelo professor-tutor da disciplina a fim de organizar a aula de leitura. Por fim, aplicar as atividades com os alunos registrando em diário de campo os procedimentos, as dificuldades e impressões sentidas durante a aplicação e trocar experiências com seus colegas por meio do fórum virtual.

O curso virtual proporcionou várias ações no sentido de promover um clima de fascínio, da importância de o professor gostar de ler para e com os seus alunos, a sensibilização para as histórias narradas e a importância de estratégias para a compreensão do texto lido.

Para o planejamento das ações de leitura, explicita-se o trabalho realizado com o texto Dormir fora de casa de Ronaldo Simões Coelho utilizado durante o curso para a elaboração das atividades de leitura com os alunos do $3^{\circ}$ ano do Ensino Fundamental.

\section{Trabalhando a leitura e suas implicações}

Seguindo as estratégias de leitura, é preciso ter claro que o aluno necessita de um motivo, de uma situação para ler. Então cabe ao professor, neste caso, ao aluno de Pedagogia, proporcionar o clima adequado para o início da leitura; são as atividades anteriores ao texto.

\section{Antes do texto:}

1) Você já dormiu fora de casa?

2) Se você for dormir fora de casa o que você leva em sua bagagem?

Durante a leitura, é aconselhável o professor utilizar as estratégias de leitura, levantar hipóteses de 
compreensão, constatar e confrontar as hipóteses levantadas pelos alunos.

\section{Dormir fora de casa}

(Ronaldo Simões Coelho. Dormir fora de casa. São Paulo, FTD, 1988)

Após a leitura do texto, é chegada a hora de trabalhar as questões de compreensão e interpretação textual, são questões que dizem respeito ao texto, aos acontecimentos que envolvem o tema central, a implicações, às inferências, às deduções, confirmações sobre a leitura no campo da compreensão.

Para romper com as questões puramente explícitas, é possível formular questões interpretativas como colocar-se no lugar do personagem, imaginar outras situações vividas no campo pessoal.

\section{Estudo do texto:}

a) Do que trata o texto?

b) Como a menina ficou ao receber o convite de sua colega? Por quê?

c) Por que a mãe da menina retirou de sua bolsa alguns objetos?

d) Que objetos poderiam ser?

e) Qual o motivo da menina ter ficado triste quando começou a anoitecer? E o que ela fez?

f) Você acredita que se fosse um menino dormindo fora de casa teria o mesmo comportamento? Por quê?

g) Você já passou por uma situação igual a vivida pela menina da história? Conte como foi?

Para questões de análise linguística, é importante diagnosticar o nível da turma, as dificuldades apresentadas e mesmo os objetivos de ensino a que se propõe. Não se trata de trabalhar o texto como pretexto para ensinar questões gramaticais, mas trabalhar com a análise, a reflexão dos usos da língua, como o tempo verbal é construído no texto, a utilização dos advérbios, a importância dos sinais de pontuação, a escolha de determinados vocábulos, todo esse trabalho é de extrema importância para que o aluno possa gradativamente familiarizar-se com os usos da língua e construir sua competência linguística.

\section{Análise linguística}

\section{1) Observe:}

Fez uma carinha boa e pediu:

- Posso telefonar pra mamãe?

a) O que significam os dois pontos nesta passagem?

b) $\mathrm{O}$ indica o travessão na fala da menina?

c) Por que a fala da menina começa com letra maiúscula?

2) No trecho: Dormir fora de casa não estava lhe parecendo, agora, tão bom como havia pensado.

a) Que outras expressões podem substituir a palavra destacada?

b) Em que momento a menina foi percebendo que não era tão bom dormir fora de casa? Por quê?

c) A história aconteceu no tempo:

( ) passado ( ) presente ( ) futuro

Indique expressões que comprovem sua resposta?

3) Explique com suas palavras o trecho: $\mathrm{O}$ sono chegou devagarzinho?

4) Complete a frase com o sinônimo da palavra entre parênteses.

a) A menina ficou com o convite. (entusiasmada)

b) A mãe a bagagem. (examinou)

c) Ela carregou sua boneca .(predileta)

5) Escreva $\mathrm{V}$ se a frase for verdadeira ou $\mathrm{F}$ se for falsa:

( ) A menina sempre dormia fora de casa.

( ) A mãe modificou a bagagem da menina.

( ) A menina levou sua boneca preferida.

( ) A menina resolveu não ir para a casa da amiga

6) Enumere as frases abaixo, de 1 a 5, de acordo com a ordem dos

acontecimentos no texto:

( ) A mãe não estava em casa.

( ) A menina telefonou para a mãe.

( ) A menina resolveu agüentar firme

( ) A menina distraiu-se com os brinquedos

( ) A menina estava com vontade de chorar, ficou triste sem graça. 
Depois de trabalhadas as questões de leitura e análise linguística, é o momento de propor as atividades para além do texto: a produção textual. Para que essa atividade seja desafiadora e estimulante, é preciso preparar o ambiente da produção de texto, criar uma situação para escrever, para quem, com que finalidade, como - neste aspecto é necessário atender as questões do gênero textual- e a circulação do texto.

\section{Depois do texto}

\section{Produção textual:}

1) De acordo com o texto a menina sentiu vontade de chorar e ligou para a sua mãe. Se a mãe tivesse atendido o telefone, como teria sido a conversa?

Escreva um diálogo entre as duas. (É necessário explicitar os recursos necessários no diálogo)

2) Agora é a vez da menina convidar sua amiga para dormir em sua casa, crie um convite para este momento especial. (É importante lembrar que o professor já deve ter trabalho o gênero Convite para solicitar a atividade)

Além da leitura do texto, houve a preocupação de planejar aula de leitura organizada, refletindo sobre os momentos de sua aplicação, utilizando estratégias que auxiliassem os alunos na compreensão de suas leituras.

Michel de Certeau(1994) refere-se à leitura como " uma operação de caça", indicando que o ato de ler não é um resultado mágico da reunião de letras em sílabas em palavras, e muito menos captação do significado do texto na sua totalidade. A leitura é prática criadora, atividade produtora de sentidos não pretendidos e, portanto, singulares, inusitados. (SAVELI, 2007, p.125)

\section{Considerações finais}

"Me senti a autora da minha própria prática." Essas foram as palavras mais enfáticas de uma aluna ao final do curso em um fórum interativo, sentir-se autora de sua prática remete a ideia de que é possível criar ações que contemplem a leitura, que auxiliem o aluno a compreender o que se está lendo.

Outro ponto importante foi o fato de os alunos do Curso de Pedagogia compreenderem que o trabalho com a leitura é essencial para a formação dos alunos, não se trata de deixar os alunos lerem sozinhos e depois solicitar uma atividade burocrática para preencher o espaço da leitura, o que normalmente acontece; Depois do curso, os alunos entenderam que utilizar estratégias de leitura - auxiliando os alunos durante o processo de leitura, chamando a atenção para as passagens mais importantes do texto, levantando hipóteses, fazendo inferências, testando a compreensão e comprovando as hipóteses levantadas- pode contribuir para que as ações apontem caminhos para a compreensão e a atribuição de sentidos.

Neste sentido, ressalta-se que o curso contribui para a formação continuada, através da troca de experiências entre os participantes, uma estreita relação entre educação básica e universidade se formou, favorecendo o crescimento profissional, a sensibilização para o outro, auxiliando-o em suas dificuldades. A leitura pode ser considerada o eixo propulsor do conhecimento, mas para que isso aconteça é necessário um trabalho conjunto. Ler e escrever não são apenas habilidades linguísticas, mas ferramentas para a formação de alunos reflexivos e atuantes no seu contexto social.

\section{Referências}

BAKHTIN, M. Marxismo e filosofia da linguagem. 6 ed. Tradução de Michel e Yara Vieira. São Paulo: HUCITEC, 1992.

BRASIL, Ministério da Educação. Secretaria de Ensino Fundamental. Parâmetros Curriculares Nacionais Língua Portuguesa. Brasília: MEC/SEF, 1997.

CAGLIARI, L. C.. Alfabetização e Linguística. São Paulo: Scipione, 1997.

CÂNDIDO, A. Direitos Humanos e literatura. In: BRASIL. Ministério da Educação, Secretaria da Educação Básica. Orientações Curriculares para o Ensino Médio. Brasília: MEC/SEB, 2006. Vol. 1 ( Linguagens, Códigos e suas tecnologias)

COELHO, R. S. Dormir fora de casa. São Paulo, FTD, 1988 .

DELMANTO, D. A leitura em sala de aula. Na Ponta do Lápis. Almanaque do Programa Escrevendo o Futuro. Ano III, n5, abril, 2007.p.13.

FOUCAMBERT, J.A criança, o professor e a leitura. Porto Alegre. RS: Artes Médicas, 1998. 
GIL, A. C. Como elaborar projetos de pesquisa. São Paulo: Atlas, 1996.

HILA, C.V.D. Ressignificando a aula de leitura a partir dos gêneros textuais. In: NASCIMENTO, E.L. (org) Gêneros textuais: da didática das línguas aos objetos de ensino. São Carlos: Editora Claraluz, 2009.

KLEIMAN, A. Oficina de leitura: teoria e prática. 4 ed. Campinas: Pontes, 1996.

Texto e leitor: aspectos cognitivos da leitura. $7 \mathrm{ed}$. Campinas, SP: Pontes, 2000.

KRAMER, S. Leitura e escrita como experiência: seu papel na formação de sujeitos sociais. In: Presença Pedagógica, v.6 n 31, jan./fev, 2000. Disponível em: www. presencapedagogica.com.br/capa6/artigos/31.pdf. Acesso em junho de 2012.

MARTINS, M.H. O que é leitura. 10 ed. São Paulo: Brasiliense, 1988.

PARANÁ, SEED/DEB. Diretrizes Curriculares da Educação Básica. Língua Portuguesa. Curitiba: SEED, 2008.

PARANÁ, SEED/DEB. Leitura, livros e leitores: considerações sobre a leitura em geral e no universo escolar. (Texto para discussão). ARIAS, V. et. al. Curitiba, mar.2012.

SAVELI, E. de L. Por uma pedagogia da leitura: reflexões sobre a formação de leitor. In: CORREIA,D.A.;SALEH, P.B.de O.(org) Práticas de letramento no ensino: leitura, escrita e discurso. São Paulo: Parábola Editorial; Ponta Grossa, PR: UEPG, 2007.

SOLÉ,I. Estratégias de leitura. 6 ed. Tradução de Cláudia Schilling. Porto Alegre,

RS: Artmed, 1998.

Submetido: 03/2014

Aprovado: 11/2014 